\title{
Production Decision and Coordination Mechanism of Socially Responsible Closed-Loop Supply Chain
}

\author{
Xiaofeng Long $\left(\mathbb{D},{ }^{1,2}\right.$ Jiali Ge $\mathbb{D}^{3},{ }^{3}$ Tong Shu $\mathbb{D}^{3},{ }^{3}$ and Chunxia Liu $\mathbb{D}^{1}$ \\ ${ }^{1}$ Department of Business Administration, Hunan University of Finance and Economics, Changsha, Hunan 410205, China \\ ${ }^{2}$ School of Economics and Trade, Hunan University, Changsha 410082, China \\ ${ }^{3}$ School of Business Administration, Hunan University, Changsha 410082, China \\ Correspondence should be addressed to Xiaofeng Long; 47387681@qq.com and Jiali Ge; logjiali@163.com
}

Received 21 January 2020; Revised 20 April 2020; Accepted 29 April 2020; Published 23 May 2020

Guest Editor: Baogui Xin

Copyright (c) 2020 Xiaofeng Long et al. This is an open access article distributed under the Creative Commons Attribution License, which permits unrestricted use, distribution, and reproduction in any medium, provided the original work is properly cited.

Corporate social responsibility (CSR) has a significant impact on the operation of enterprises. This study analyzes the production and coordination decisions of closed-loop supply chain (CLSC) by establishing two assumptions of endogenous and exogenous CSR. The results reveal that, for ordinary consumers, CSR is quantified as the parameter of consumer surplus, which has an impact on the patent licensing fee, revenue-sharing ratio, and so on, and which not only increases the sales quantity in CLSC but also creates more value for the manufacturer and the retailer. Considering endogenous CSR, the study found that the manufacturer's CSR level and the manufacturer's and the retailer's profits both increase with the proportion of CSR-sensitive consumers. In the endogenous model, the manufacturer sets a higher wholesale price and lower patent licensing fee than in the exogenous model. Perfect coordination in the two models can be achieved by setting a revenue-sharing ratio related to wholesale price and patent licensing fee. In practice, improving the social responsibility consciousness of consumers and raising enterprises' CSR level can achieve a win-win situation for revenues and social welfare.

\section{Introduction}

In the new era, increasing attention has been paid to environmental sustainability, driven by laws, regulations, environmental pressure, and social responsibility, which has become an important indicator of supply chain management success [1]. Sustainable supply chain management focuses on environmental issues, such as closed-loop supply chain (CLSC) and corporate social responsibility (CSR).

CSR is a type of intrinsic motivation [2], which refers to an enterprise not only creating profits for shareholders but also emphasizing contributions to the environment, consumers, and society. Consumers with CSR awareness can obtain utility from the environmental attributes of products, such as remanufactured products, which is an important market driver for environmental sustainability in supply chains. According to Cotte and Trudel [3], a total of 70\% of consumers are willing to pay higher prices for products with "responsible" attributes. Most consumers tend to buy products that are socially responsible and environmentally friendly [4]. This depends in part on the CSR level of the manufacturer.

Enterprises' recycling and reuse process is also a means of strengthening their level of CSR. Enterprises can achieve the improvement and coordination of supply chains through joint CSR investments [5-7]. The manufacturer's CSR behavior is beneficial to increase channel profit and improve the recovery rate [8], and CSR investment is a feasible strategy to enhance enterprises' sales power [9].

Based on theoretical research, this study constructs CLSC production and collaboration optimization models considering CSR and examines the following questions: (1) how does endogenous and exogenous CSR affect pricing, revenue of CLSC members? (2) what are the impact and coordination functions of patent licensing fee on the decision of CLSC? (3) what is the influencing mechanism of different types of consumers on CSR and the profit of the manufacturer and the retailer? 
The main contributions of this study are as follows: (1) it brings CSR behaviors into the classic framework of CLSC management, examines its impact on the operation of CLSC, and clarifies the value of CSR; (2) it considers the issue of patent licensing in CLSC and reveals the regulatory role of patent licensing; and (3) it sets a revenue-sharing ratio related to price and patent licensing fee in the two models to coordinate the profit of the manufacturer and the retailer.

The remainder of this paper is organized as follows: the related research is reviewed in Section 2, Section 3 outlines the model setting, Section 4 investigates the decision and coordination in the CLSC of exogenous CSR when there are only ordinary consumers in the market, Section 5 examines the decision and coordination in the CLSC of endogenous CSR when there are CSR-sensitive consumers and ordinary consumers in the market, and concluding remarks are presented in Section 6.

\section{Literature Review}

There are three streams of research related with this research: CLSC considering patent licensing, CSR activities in supply chain management, and supply chain coordination.

The first stream mainly focuses on CLSC considering patent licensing, which can be a strategy when there are multiple remanufacturing subjects in CLSC. Cruz [10] studied the impact of CSR in supply chain management using a multicriteria decision-making approach. Zhao et al. [11] investigated the best patent licensing contracts with network effects and investigated the welfare impact by setting a Stackelberg model. Huang and Wang [12] examined the CLSC model for product recycling and hybrid remanufacturing under patent licensing and discussed the impact of remanufacturing capabilities on supply chain members and environmental sustainability. Hong et al. [13] studied the quantity and collective decisions in the CLSC using two licensing models: fixed fees and unit royalty. Hao et al. [14] discussed the best game strategies for both parties under three different decision structures: two competitive models (competition with and without remanufacturing patent licensing) and cooperation models. Huang and Wang $[12,15]$ studied a CLSC with technology licenses. Jin et al. [16] considered the two-period game model, designed the optimal patent licensing contract and production outsourcing strategy, and analyzed the value of CSR.

The second stream is CSR activities in supply chain management. $\mathrm{Ni}$ and $\mathrm{Li}$ [17] investigated how enterprises and suppliers interact in CSR behaviors and the impact of external parameters on this interaction. Panda [18] found that revenue-sharing contracts can maximize CSR retailers' welfare. Modak et al. [19] analyzed the dual-channel supply chain of CSR and studied its impact on the successful operation of the dual channel. Panda et al. [20] discussed the issue of coordination and profit distribution in the supply chain composed of CSR manufacturer and retailer. Panda and Modak [21] examined the channel coordination and benefit distribution between CSR manufacturer and retailer through subgame perfect equilibrium and negotiations. White et al. [22] summarized the studies on CSR through quantitative and qualitative models. Modak et al. [23] studied CSR practice in a two-echelon CLSC.

The third stream is supply chain coordination. Panda et al. [24] resolved channel conflicts and distributed surplus profits among channel members by Nash bargaining contracts. Zhang and Ren [25] studied CLSC coordination strategy for the remanufacture of patented products. Panda et al. [8] discussed the channel coordination issue of CLSC by setting a revenuesharing contract. Seyedhosseini et al. [26] proposed a two-part tariff contract to provide a win-win situation for all supply chain members. Hosseini-Motlagh [27, 28] studied CLSC coordination of CSR considering different demand conditions. $\mathrm{Li}$ and Gong [29] constructed a CLSC model and designed a cost-sharing contract to achieve supply chain coordination.

The related literature mainly examines the impact of CSR on supply chain performance, decisions, and coordination. These studies reveal that environmental improvement can be obtained through supply chain management. The current study focuses on the production decision and coordination mechanism of CLSC with patent licensing from the perspective of CSR. In addition, this study considers two models of endogenous and exogenous CSR and types of customers in the market to better grasp the value of CSR. Our study differs from the existing literature in that enterprises' CSR and the social responsibility awareness of consumers are involved in the model. The related theoretical and numerical analysis reveal how the endogenous and exogenous CSR influence production decisions and coordination.

\section{Model Setting}

We establish a CLSC composed of a manufacturer and a retailer, in which the manufacturer sells new products through the retailer, and the retailer recycles used products from consumers, reselling them to consumers after remanufacturing. There are two types of consumers in the market: CSR-sensitive consumers (C-type consumers), which account for a ratio of $\rho$ to market capacity, and ordinary consumers (N-type consumers), which account for a ratio of $1-\rho$ to market capacity. The characteristic of C-type consumers is that they can obtain additional utilities by choosing products produced by a CSR manufacturer. The utility C-type consumers can obtain from buying a unit of CSR-type products is $U_{C}=v-p_{c}+K y_{m}$. $\mathrm{N}$-type consumers are only sensitive to product price, and the utility they can obtain from buying a unit of ordinary products is $U_{N}=v-p_{n}$. Conditions for C-type consumers purchasing CSR products is $U_{C}>0$ and $U_{C} \geq U_{N}$. Conditions for N-type consumers purchasing ordinary products is $U_{N}>0$ and $U_{N}>U_{C}$, in which $v \sim U[0,1]$. Through calculation, we find the following:

(1) When $v-p_{c}+K y_{m} \geq v-p_{n}$, the market demand for CSR-type products is $q_{c}=a \rho\left(1-p_{c}+K y_{m}\right)$ and the market demand for ordinary products is $q_{n}=a(1-\rho)\left(1-p_{n}\right)$.

(2) When $v-p_{c}+K y_{m}<v-p_{n}$, consumers will not buy CSR products and all consumers will buy ordinary products. At this time, the market demand for CSR-type products is $q_{c}=0$ and the market demand 
for ordinary products is $q_{n}=a\left(1-p_{n}\right)$. Model parameter settings are presented in Table 1 .

\section{Production Decision and Coordination Mechanism of CLSC Based on Exogenous CSR}

This section does not distinguish between consumer groups, meaning that consumers do not know whether the enterprise has social responsibility. In addition, this section explores the impact of CSR on patent licensing, recycling rates, and profits. The CSR manufacturer will encourage the retailer to recycle, produce, or sell more remanufactured products while increasing the revenues of all parties [8]. We use $\theta \in[0,1]$ to represent the CSR factor of the manufacturer, $\theta=0$ is the revenue maximization of the manufacturer, and $\theta=1$ is the welfare maximization of the manufacturer.

In the manufacturer's revenue function, the manufacturer's CSR is quantified as the proportion of consumer surplus (CS), which refers to the difference between the maximum price a consumer is willing to pay and the actual total price to pay. When the demand function is the linear function $D=a(1-p)$, CS is CS $=\int_{(a-D) / a}^{a}(a-$ ap) $\mathrm{d} p=\left(D^{2} / 2 a\right)$ [8]. Some of the assumptions used herein are as follows:

Assumption 1: the manufacturer is the leader of the Stackelberg game.

Assumption 2: remanufactured products are used as products recycled from consumers by the retailer. To ensure the remanufacturing activities of the retailer, the saving value of remanufactured products is $\Delta>0$.

Assumption 3: remanufactured products have no difference in quality and use function compared with new products produced by the manufacturer; consumers value both products in the same way, and they are sold at the same price in the market.

The recycling quantity of used products increases with the increase in recovery price [30]; the recycling quantity of used products $G$ is a function of the recovery price $r$ : $G=\alpha+\beta * r$, where $\alpha$ represents the quantity of used products that consumers voluntarily return and $\beta$ indicates consumers' degree of sensitivity to recovery prices.

4.1. Analysis of Decentralized Decision Model. The manufacturer authorizes the retailer to remanufacture, charging a certain patent licensing fee. In addition, the manufacturer may not recycle or remanufacture products for the sake of recovery costs or branding. The retailer recycles used products from remanufacturing activities and sells new and remanufactured products together to consumers after obtaining a patent technical license.

The decision turn of the Stackelberg game is as follows: (1) as the game leader, the manufacturer first sets the wholesale price $w$ and patent licensing fee $f ;(2)$ after obtaining the manufacturer's patent licensing, the retailer determines the sale price of the product $p$ and recovery price $r$. When CSR is not considered, the manufacturer's revenue function is

$$
\max _{w, f} \pi_{M}=\left(w-c_{n}\right)(a-a * p-\alpha-\beta * r)+f *(\alpha+\beta * r),
$$

and the retailer's revenue function is

$$
\begin{aligned}
\max _{p, r} \pi_{R}= & (p-w)(a-a * p-\alpha-\beta * r) \\
& +\left(p-c_{n}+\Delta\right)(\alpha+\beta * r)-(f+r)(\alpha+\beta * r) .
\end{aligned}
$$

When CSR is considered, the manufacturer's revenue function is

$$
\begin{aligned}
\max _{w, f} v_{M}= & \left(w-c_{n}\right)(a-a * p-\alpha-\beta * r) \\
& +f *(\alpha+\beta * r)+\theta * \frac{D^{2}}{2 a} .
\end{aligned}
$$

Proposition 1 can be obtained by the backward induction solution.

Proposition 1. The revenue functions of the manufacturer and the retailer under decentralized decisions are nonconvex. The optimal wholesale price can be obtained as follows: $w^{*}=\left(\left(2-\theta+2 c_{n}\right) /(4-\theta)\right)$, the optimal retail price is $p^{*}=\left(\left(3-\theta+c_{n}\right) /(4-\theta)\right)$, the optimal recovery price is $r^{*}=((\beta \Delta-3 \alpha) / 4 \beta)$, and the optimal patent licensing fee is $f^{*}=\left(\left(4 \beta+4 \alpha-2 \beta \theta-\alpha \theta-4 \beta c_{n}+4 \beta \Delta+2 \beta c_{n} \theta-\beta \theta \Delta\right) /\right.$ $(2 \beta(4-\theta)))$.

By Proposition 1, the maximum revenue of the manufacturer considering CSR is

$$
v_{M}^{*}=\frac{a \alpha^{2}+2 a \alpha \beta \Delta-4 \beta \alpha^{2}}{8}+\frac{\beta^{2} \Delta^{2}}{a \beta}-a^{2} \beta c_{n}+\frac{a c_{n}^{2}}{2(4-\theta)} .
$$

The maximum revenue of the retailer is

$$
\pi_{R}^{*}=\frac{(\beta \Delta+\alpha)^{2}}{16 \beta}+\frac{\alpha^{2}-2 a^{2} c_{n}+a^{2} c_{n}^{2}}{a(4-\theta)^{2}} .
$$

The total revenue of the supply chain is

$$
\begin{aligned}
v^{*}= & \frac{(\beta \Delta+\alpha)^{2}}{16 \beta}+\frac{\alpha^{2}-2 a^{2} c_{n}+a^{2} c_{n}^{2}}{a(4-\theta)^{2}}+\frac{a \alpha^{2}+2 \alpha a \beta \Delta-4 \beta \alpha^{2}}{8} \\
& +\frac{\beta^{2} \Delta^{2}}{a \beta}-\beta a^{2} c_{n}+\frac{a c_{n}^{2}}{2(4-\theta)} .
\end{aligned}
$$

The CS is

$$
\mathrm{CS}=\frac{a\left(1-c_{n}\right)^{2}}{2(4-\theta)^{2}}
$$

Conclusion 1. (1) As the cost of new products increases, both wholesale and retail prices increase, the optimal patent licensing fee charged by the manufacturer decreases, the revenue of the manufacturer and the retailer decreases, and the revenue of the supply chain decreases. (2) As the 
TABLE 1: Model parameter settings.

\begin{tabular}{lr}
\hline Parameter & Represents \\
\hline$p$ & Retail price per unit of product set by the retailer \\
$w$ & Unit wholesale price given by the manufacturer \\
$r$ & Recovery price for used products \\
$c_{n}$ & Production cost of new products \\
$\Delta$ & Production cost saved by the retailer from remanufactured products \\
$K$ & Impact factors of social responsibility level on consumers' willingness to pay \\
$f$ & Patent licensing fee for manufacturer-licensed remanufacturing \\
$y_{m}$ & Manufacturer's level of CSR \\
$\rho$ & Ratio of CSR-sensitive consumers \\
$\pi_{i}^{j}$ & Market capacity \\
$\pi_{i}$ & The profit function of the enterprise $i$, parameter $i \in\{M, R\}$, where $M$ represents the manufacturer and $R$ represents the retailer
\end{tabular}

remanufacturing saving cost increases, the recovery price and recycling quantity of used products both increase, the patent licensing fee charged increases and the profits of the manufacturer, the retailer, and the supply chain all increase. (3) When the manufacturer shows stronger CSR, the wholesale and the retail prices of products are lower. The manufacturer's revenue is higher, the patent licensing fee is lower, the retailer's revenue increases, and CS increases.

4.2. Analysis of Centralized Decision Model. In the centralized decision model, the revenue function of the entire supply chain is

$$
\max _{p_{c}, r_{c}} \pi_{c}=\left(p_{c}-c_{n}\right)(a-a * p)+\left(\Delta-r_{c}\right)\left(\alpha+\beta * r_{c}\right) .
$$

When the manufacturer' CSR is considered, the revenue function of the entire supply chain is

$$
\max _{p_{c}, r_{c}} v_{c}=\left(p_{c}-c_{n}\right)(a-a * p)+\left(\Delta-r_{c}\right)\left(\alpha+\beta * r_{c}\right)+\theta * \frac{D^{2}}{2 a} .
$$

Take the partial derivatives of formula (8) with respect to $p_{c}$ and $r_{c},\left(\partial v_{c} / \partial p_{c}\right)=0,\left(\partial v_{c} / \partial r_{c}\right)=0$, and obtain the best solution $p_{c}^{*}$ and $v_{c}^{*}$. The corresponding Hessian matrix is

$$
H_{c}=\left(\begin{array}{cc}
\frac{\partial^{2} v_{c}}{\partial p_{c}^{2}} & \frac{\partial^{2} v_{c}}{\partial p_{c} \partial r_{c}} \\
\frac{\partial^{2} v_{c}}{\partial r_{c} \partial p_{c}} & \frac{\partial^{2} v_{c}}{\partial r_{c}^{2}}
\end{array}\right)=\left(\begin{array}{cc}
-2 \beta & -2 \beta \\
0 & a \theta-2 a
\end{array}\right) .
$$

When Hessian matrix $H_{c}>0,2-\theta>0$, that is, the centralized revenue function is nonconvex, we can obtain Proposition 2.

Proposition 2. The revenue function of the entire supply chain under centralized decisions with respect to $p_{c}$ and $r_{c}$ is nonconvex, and the optimal solution $\left(p_{c}^{*}, r_{c}^{*}\right)$ is $\left(\left(\left(1-\theta+c_{n}\right) /(2-\theta)\right),((\beta \Delta-\alpha) / 2 \beta)\right)$. The revenue of the entire supply chain under centralized decisions is

$$
v_{c}^{*}=\frac{2 a \beta+2 \alpha^{2}+2 a \beta c_{n}^{2}+2 \beta^{2} \Delta^{2}-\beta \alpha^{2}-\theta \beta^{2} \Delta^{2}-4 \beta c_{n}+4 \alpha \beta \Delta-2 \alpha \beta \Delta \theta}{4 \beta(2-\theta)} .
$$

4.3. Revenue-Sharing Coordination Mechanism. Traditionally, the manufacturer and the retailer act independently and maximize their own respective revenues. However, an effective supply chain network requires a cooperative relationship. Therefore, a coordination mechanism is needed to coordinate the manufacturer and the retailer. Under a revenue-sharing (RS) contract, the manufacturer offers a wholesale price and requires a small portion of the revenue from the retailer. The RS contract sets the revenue-sharing parameter as $\lambda \in(0,1)$, and the manufacturer receives (1$\lambda)$ of the revenue.

Proposition 3. Under the $R S$ contract, the revenue function expressions of the manufacturer and the retailer are, respectively, as follows:

$$
\begin{aligned}
\pi_{M}= & (1-\lambda) p(a-a p)+\left(w-c_{n}\right)(a-a p-\alpha-\beta r) \\
& +f(\alpha+\beta r), \\
\pi_{R}= & (\lambda p-w)(a-a p)+\left(w-c_{n}+\Delta\right)(\alpha+\beta r) \\
& -(f+r)(\alpha+\beta r), \\
v_{M}= & (1-\lambda) p(a-a p)+\left(w-c_{n}\right)(a-a p-\alpha-\beta r) \\
& +f(\alpha+\beta r) \frac{\theta(a-a p)^{2}}{2 a} .
\end{aligned}
$$

When the RS contract the manufacturer provided to the retailer is 


$$
\left(w^{\mathrm{co}}, f^{\mathrm{co}}\right)=\left(\frac{2 c_{n}-\theta}{2-\theta} \lambda, \frac{2 c_{n}-\theta}{2-\theta} \lambda-c_{n}\right),
$$

the RS proportion $\lambda$ should meet $\lambda_{1}<\lambda<\lambda_{2}$, in which when

$$
\begin{aligned}
& \lambda_{1}=\frac{(2-\theta)^{2}\left(16\left(a-a c_{n}\right)^{2}-3 a(4-\theta)^{2}(\alpha+\beta \Delta)^{2}\right.}{16 \beta(4-\theta)^{2}\left(a-a c_{n}\right)^{2}}, \\
& \lambda_{2}=-\left(\frac{\left(1-c_{n}\right)^{2}}{2(\theta-2)}+\frac{4 \beta\left(1-c_{n}\right)^{2}+(4-\theta)(\alpha+\beta \Delta)^{2}-3 \beta^{2} \Delta^{2} \theta}{8 \beta(4-\theta)}\right) \frac{(2-\theta)^{2}}{\left(a-a c_{n}\right)^{2}},
\end{aligned}
$$

the CLSC can be coordinated by the RS contract (see Appendix A).

Proposition 4. Under the RS contract, it satisfies the following relationships: $p^{c o}<p^{*}, w^{c o}<w^{*}, f^{c o}<f^{*}, r^{c o}>r^{*}$, $\pi_{R}^{c o}>\pi_{R}^{*}$, and $v_{M}^{c o}>v_{M}^{*}$.

Proposition 4shows that when an RS contract is adopted, the manufacturer pays more attention to CSR and reduces its wholesale price and the product patent licensing fee, thus increasing the sales volume of products. Product sales are directly proportional to the CSR level of the manufacturer. In addition, the recycling intensity of the retailer increases, and in response to the manufacturer's strategies, the retailer reduces their sale prices to encourage customers to buy more products and puts more efforts into collecting used products from customers. The manufacturer's CSR therefore influences the retailer's decisions and further influences their decisions in the reverse supply chain through influencing prices. In centralized decisions, when CSR increases, the manufacturer reduces the wholesale price of products, and the sale price under the centralized decision is lower than that under the decentralized decision. As a result, there is a higher demand for products of centralized decisions. Obviously, the retailer will make more efforts to collect used products under centralization. The manufacturer, the retailer, and the entire supply chain have higher revenues under the centralized model than that under decentralized model; thus, the entire CLSC achieves coordination.

At the same time, consumers can buy new products at a lower price and sell used products at a higher price, which greatly improves consumers' utilities and achieves a win-win situation for enterprises and consumers.

4.4. Numerical Examples and Sensitivity Analysis. Numerical calculations are made based on the above conclusions. Parameter values refer to assumptions of Bakal and Akcali [30]; the market demand function of products is $D(p)=100(1-p)$, the supply function of old products is $G(r)=0.8+10 r$, and the production cost of new products is $C_{n}=0.5$. The decision results of different CLSC systems are illustrated in Tables 2 and 3.

As can be seen from Table 2, under decentralized decisions, with the increasing awareness of the manufacturer's CSR, the revenues of both the manufacturer and the retailer increase, the manufacturer reduces the patent licensing fee and lowers the wholesale prices so that the retailer sets retail prices lower and the consumer purchase quantity increases. With the increase in remanufacturing saving cost, the retailer's recycling prices rise. The manufacturer charges more patent licensing fees, and both the manufacturer's and the retailer's revenues increase. From Table 3, as the RS proportion increases, the manufacturer's wholesale price increases, the patent licensing fee decreases, the retailer's revenue increases, and the manufacturer's revenue decreases.

Sensitivity analysis is conducted on the key parameters $\left(C_{n}\right.$ and $\left.\theta\right)$ to examine the proposed models' performance. The effects of $C_{n}$ on the $w, p$, and $f$ are shown in Figure 1. By increasing $C_{n}$, both wholesale prices $w$ and retail prices $p$ increase and the optimal patent licensing fee $f$ decreases. When the production cost of new products $C_{n}$ is higher, the manufacturer reduces the patent licensing fee to encourage the retailer to produce and recycle more used products and increase the revenue. Figure 2 illustrates the effects of $\theta$ on the $w, p$, and $f$ by increasing $\theta$ and the decreases in wholesale prices $w$, retail prices $p$, and patent licensing fee $f$. When the manufacturer's CSR $\theta$ is stronger, the price of products is lower. The sales volume is higher, and the profits of both the manufacturer and the retailer increase. The manufacturer will reduce the patent licensing fee, encouraging the retailer to recycle and remanufacture. Therefore, patent licensing fee is an important adjustment tool for the manufacturer.

From Figure 3, the entire CLSC profit is improved under RS contracts, the profit of the manufacturer and the retailer is improved compared to the decentralized model $\left(\pi_{R}^{\mathrm{co}}>\pi_{R}^{*}\right.$ and $v_{M}^{\text {co }}>v_{M}^{*}$ ) and the compensation-based whole price mechanism can motivate the retailer to take part in the centralized decisions.

\section{Production Decision and Coordination Mechanism of CLSC of Endogenous CSR}

This section divides consumers into CSR-sensitive and ordinary types, constructs the CLSC model considering endogenous CSR, and mainly examines the impact of the proportion of CSR-sensitive consumers on CSR level, the profits of CLSC members, and RS contracts. The specific parameter settings are shown in Table 1.

5.1. Analysis of Decentralized Decision Model. When CSR is endogenous, there are CSR-sensitive consumers and 
TABLE 2: Decentralized decision results of CLSC.

\begin{tabular}{ccccccc}
\hline \multicolumn{2}{c}{$\begin{array}{c}\text { Parameter } \\
\text { variation }\end{array}$} & $w$ & $p$ & $f$ & $\pi_{R}$ & $v_{M}$ \\
\hline$\Delta=0.3$ & $\theta=0.2$ & 0.7368 & 0.8684 & 0.4268 & 1.8216 & 3.47 \\
$\Delta=0.3$ & $\theta=0.5$ & 0.7143 & 0.8571 & 0.4043 & 2.1311 & 3.7519 \\
$\Delta=0.3$ & $\theta=0.8$ & 0.6875 & 0.8438 & 0.3775 & 2.5317 & 4.0868 \\
$\Delta=0.4$ & $\theta=0.2$ & 0.7368 & 0.8684 & 0.4768 & 1.8753 & 3.5775 \\
$\Delta=0.4$ & $\theta=0.5$ & 0.7143 & 0.8571 & 0.4543 & 2.1848 & 3.8594 \\
$\Delta=0.4$ & $\theta=0.8$ & 0.6875 & 0.8438 & 0.4275 & 2.5854 & 4.1942 \\
\hline
\end{tabular}

TABle 3: Coordinated decision results under revenue-sharing contract.

\begin{tabular}{llccccc}
\hline \multicolumn{2}{c}{ Parameter variation } & $w^{\mathrm{co}}$ & $r^{\mathrm{co}}$ & $f^{\mathrm{co}}$ & $\pi_{R}^{\mathrm{co}}$ & $v_{M}^{\mathrm{co}}$ \\
\hline$\Delta=0.3$ & $\lambda_{1}=0.2209$ & 0.0982 & 0.11 & 0.4018 & 1.8216 & 5.4839 \\
$\theta=0.2$ & $\lambda_{2}=0.4503$ & 0.2001 & 0.11 & 0.2999 & 3.8355 & 3.47 \\
$\Delta=0.4$ & $\lambda_{1}=0.1448$ & 0.0483 & 0.16 & 0.4517 & 2.1848 & 6.7245 \\
$\theta=0.5$ & $\lambda_{2}=0.4027$ & 0.1420 & 0.16 & 0.3658 & 5.0499 & 3.8594 \\
$\Delta=0.4$ & $\lambda_{1}=0.1157$ & 0.0193 & 0.16 & 0.4807 & 2.5854 & 8.4073 \\
$\theta=0.8$ & $\lambda_{2}=0.3584$ & 0.0597 & 0.16 & 0.4403 & 6.7984 & 4.1942 \\
\hline
\end{tabular}

ordinary consumers in the market, and the revenue function of the manufacturer is

$$
\begin{aligned}
\max _{w_{c}, w_{n}, f, y_{m}} \pi_{M}= & \left(w_{c}-c_{n}\right) a \rho\left(1-p_{c}+K y_{m}\right) \\
& +\left(w_{n}-c_{n}\right) a(1-\rho)\left(1-p_{n}\right) \\
& +f(\alpha+\beta r)-y_{m}^{2} .
\end{aligned}
$$

The revenue function of the retailer is

$$
\begin{aligned}
\max _{p_{c}, p_{n}, r} \pi_{R}= & \left(p_{c}-w_{c}\right) a \rho\left(1-p_{c}+K y_{m}\right) \\
& +\left(p_{n}-w_{n}\right) a(1-\rho)\left(1-p_{n}\right) \\
& +(\Delta-f-r)(\alpha+\beta r) .
\end{aligned}
$$

Proposition 5 can be obtained through the backward induction solution.

Proposition 5. The revenue functions of the manufacturer and the retailer are nonconvex. The optimal wholesale price of CSR-type products that can be obtained is $w_{c}=$ $-\left(-a c_{n} \rho K^{2}+4 c_{n}+4\right) /\left(a \rho K^{2}-8\right)$, the optimal retail price is $p_{c}=-\left(\left(2 c_{n}-a c_{n} \rho K^{2}+6\right) /\left(a \rho K^{2}-8\right)\right)$, the optimal wholesale price of ordinary products is $w_{n}=\left(\left(1+c_{n}\right) / 2\right)$, and the optimal retail price is $p_{n}=\left(\left(3+c_{n}\right) / 4\right)$. The optimal recovery price is $r=-((3 \alpha-\beta \Delta) / 4 \beta)$, the optimal patent licensing fee is $f=((\alpha+\beta \Delta) / 2 \beta)$, and the manufacturer's optimal CSR level is $y_{m}=-\left(\left(a K \rho\left(1-c_{n}\right)\right) /\left(a K^{2} \rho-8\right)\right)$. From $p_{c}>0$, $y_{m}>0,0<c_{n}<1$, we can obtain $a \rho K^{2}<8$.

\section{Conclusion 2}

(1) As the cost of products increases, the retail price and the wholesale price of ordinary products increase; when $a \rho K^{2}<4$, the wholesale price of CSR-sensitive products increases. When $4<a \rho K^{2}<8$, the wholesale price of CSR-sensitive products decreases. When

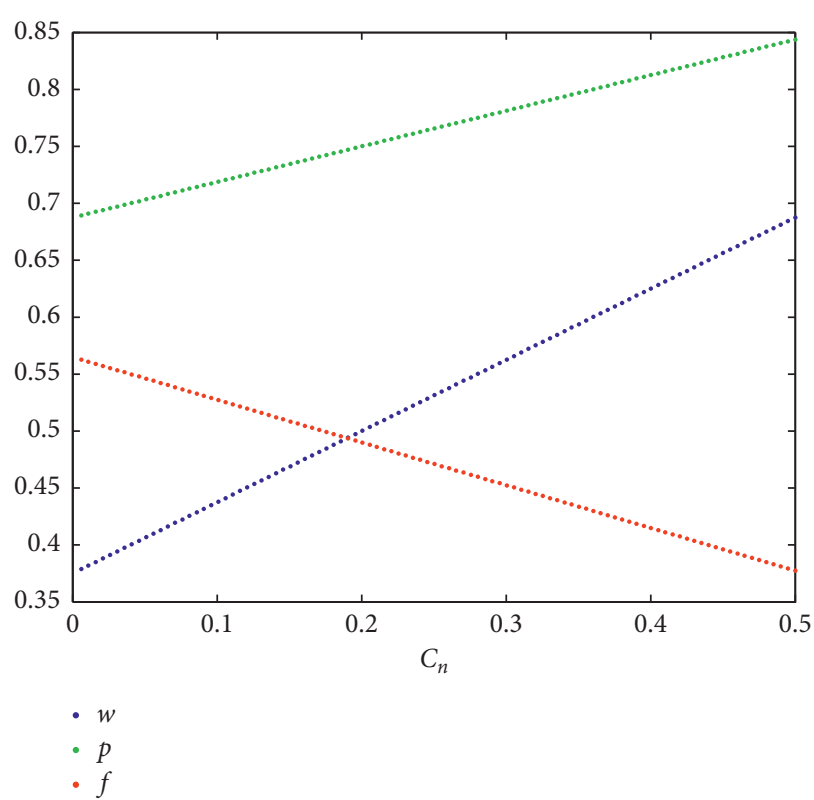

Figure 1: Optimal decision results when $C_{n}$ changes.

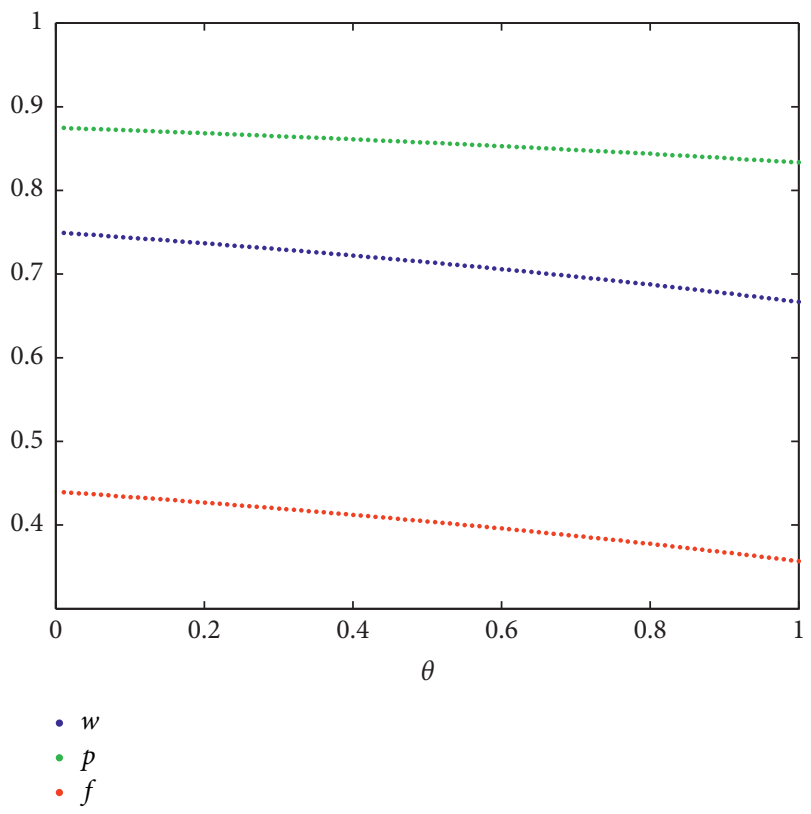

Figure 2: Optimal decision results when $\theta$ changes.

$a \rho K^{2}<2$, the retail price of CSR-sensitive products increases. When $2<a \rho K^{2}<8$, the retail price of CSRsensitive products decreases. Optimum patent licensing fee and recovery prices are not affected by the cost of products, and the manufacturer's CSR level decreases as the cost of products increases.

(2) As the remanufacturing saving cost increases, the recovery price and the recycling quantity of used products both increase, the patent licensing fee increases, and the profits of the manufacturer, the retailer, and the supply chain all increase.

(3) With the increase in the proportion of CSR-sensitive consumers, the wholesale and retail prices of CSR 


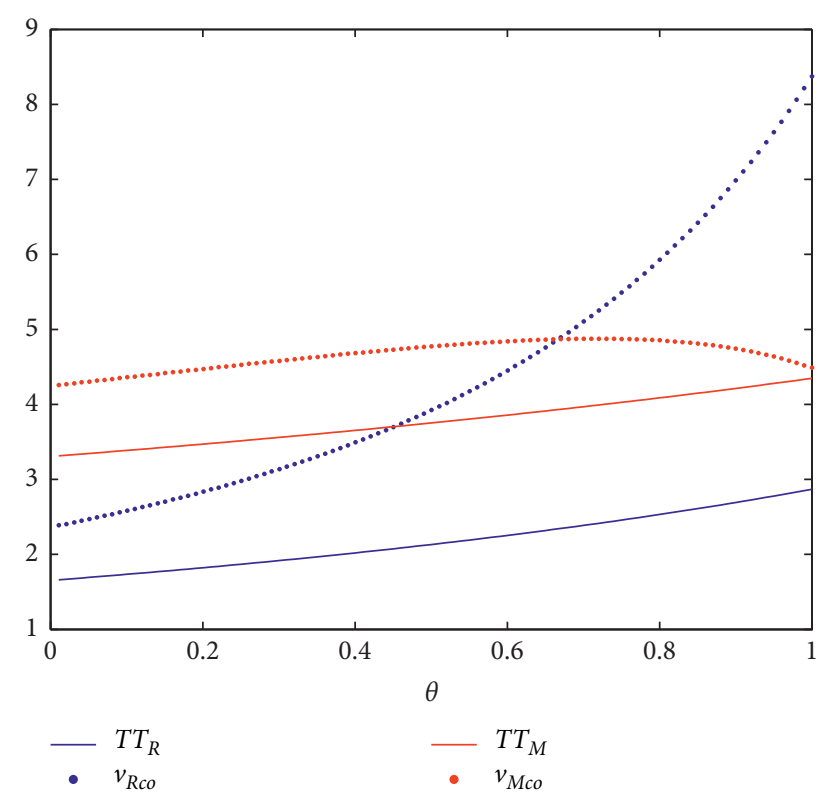

Figure 3: Profit comparison between decentralized and centralized decisions when $\theta$ changes.

products increase, the CSR level of the manufacturer increases, and the profits of both the manufacturer and the retailer increase.

(4) $w_{n}<w_{c}, p_{n}<p_{c}$, the wholesale and selling prices of socially responsible products are higher than those of ordinary products.

5.2. Analysis of Centralized Decision Model. In the centralized decision model, the revenue function of the entire supply chain is

$$
\begin{aligned}
\pi= & a \rho\left(p_{c}-c_{n}\right)\left(1-p_{c}+K y_{m}\right)+a\left(p_{n}-c_{n}\right)(1-\rho)\left(1-p_{n}\right) \\
& +(\Delta-r)(\alpha+\beta r)-y_{m}^{2} .
\end{aligned}
$$

Proposition 6. The revenue function of the entire supply chain under centralized decisions is nonconvex with respect to $p_{c}, p_{n}$, and $r$. The optimal solution of $\left(p_{c}^{*}, p_{n}^{*}, r^{*}\right)$ is $\left(-\left(\left(2-a c \rho K^{2}+2 c_{n}\right) /\left(a \rho K^{2}-4\right)\right),\left(1+c_{n}\right) / 2,(\beta \Delta-\alpha) / 2 \beta\right)$.

Proposition 7. This compares the results of decentralized and centralized decisions $p_{n}>p_{n}^{*}, r^{*}<r_{c}^{*}$. When apK $K^{2}<2$, $p_{c}>p_{c}^{*}$ and when $2<a \rho K^{2}<8, p_{c}<p_{c}^{*}$.

Conclusion 3. In the centralized decision model, (1) with the increase in remanufacturing cost savings, the maximum revenue of the entire supply chain increases and the recovery price of products increases. (2) With the increase in the proportion of CSR-sensitive consumers, the sale price of CSR products increases, and the overall revenue of the supply chain increases.

5.3. Coordination Mechanism. RS contracts are still adopted for coordination here. In RS contracts, the manufacturer

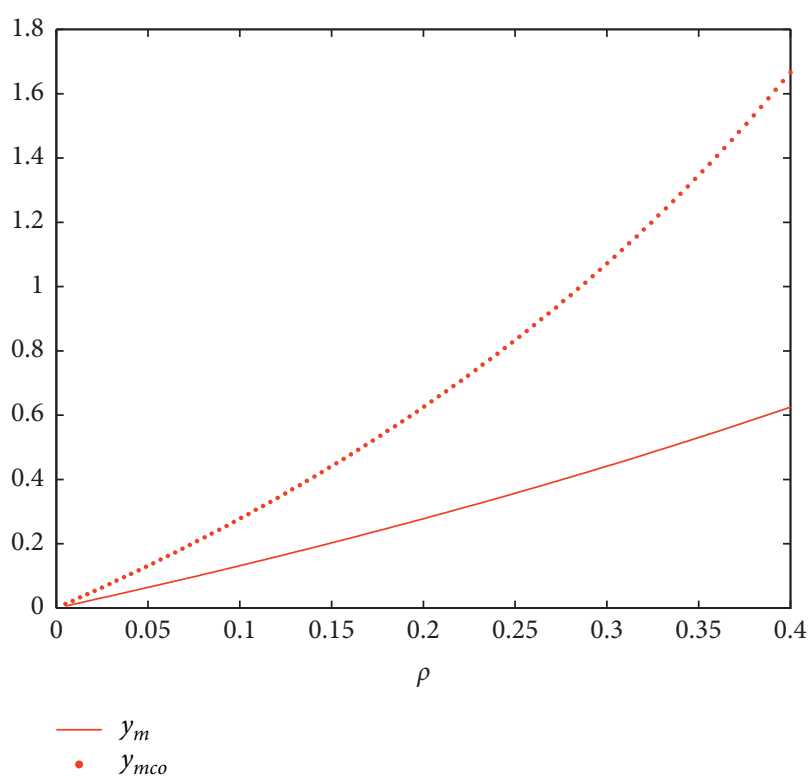

FIgURE 4: Optimal CSR results between decentralized and centralized decisions when $\rho$ changes.

provides a wholesale price and requires a portion of the revenue from the retailer. The revenue-sharing parameter set in RS contracts is $\lambda \in(0,1)$, and the manufacturer receives $(1-\lambda)$ times a portion of the revenue.

The revenue function of the manufacturer is

$$
\begin{aligned}
\pi_{M}= & (1-\lambda)\left(p_{c} a \rho\left(1-p_{c}+K y_{m}\right)+p_{n} a(1-\rho)\left(1-p_{n}\right)\right) \\
& +\left(w_{c}-c_{n}\right) a \rho\left(1-p_{c}+K y_{m}\right) \\
& +\left(w_{n}-c_{n}\right) a(1-\rho)\left(1-p_{n}\right)+f(\alpha+\beta r)-y_{m}^{2} .
\end{aligned}
$$

The retailer's revenue function is

$$
\begin{aligned}
\pi_{R}= & \left(\lambda p_{c}-w_{c}\right) a \rho\left(1-p_{c}+K y_{m}\right) \\
& +\left(\lambda p_{n}-w_{n}\right) a(1-\rho)\left(1-p_{n}\right)+(\Delta-f-r)(\alpha+\beta r) .
\end{aligned}
$$

Proposition 8. When the manufacturer offers the contract $w_{c}=-2 \lambda\left(\left(\left(2+2 c_{n}-a c_{n} \rho K^{2}\right) /\left(a \rho K^{2}-4\right)\right)+\left(\left(\lambda+K \lambda y_{m}\right) /\right.\right.$ $2 \lambda)), w_{n}=\lambda c_{n}$, and $f=((\alpha+\beta \Delta) / 2 \beta)$, the CLSC can be coordinated. See Appendix B.

5.4. Sensitivity Analysis. The data are set as in Section 4.4, $a=100, G(r)=0.8+10 r, C_{n}=0.5, \Delta=0.3$, and $k=0.2$. Sensitivity analysis is conducted on the key parameter $\rho$ to examine the proposed model's performance in the following. Figure 4 illustrates the effects of $\rho$ on $y_{m}$, and Figure 5 shows the effects of $\rho$ on the profits of the manufacturer and the retailer under the decentralized and coordinated structures. With the increase in the proportion of CSR-sensitive consumers $\rho$, the CSR level of enterprises $y_{m}$ increases and the profits of both the manufacturer and the retailer increase, which are more than those in the decentralized structure. 


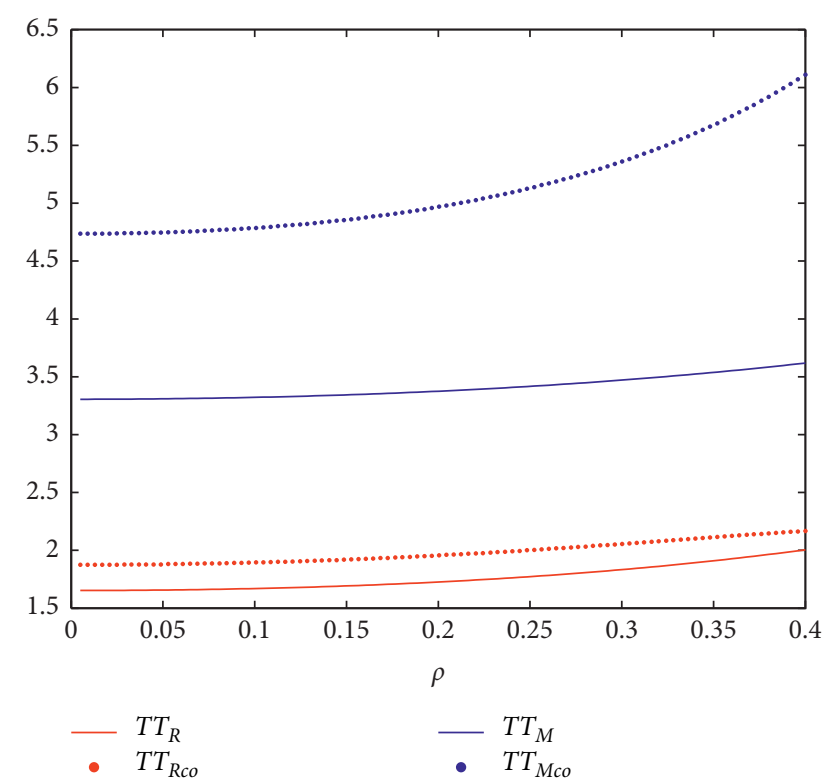

Figure 5: Profit comparison between decentralized and centralized decisions when $\rho$ changes.

The result confirms those of Hosseini-Motlagh et al. [28], who used the cost-sharing contract to coordinate the CLSC.

Comparing the wholesale price, patent licensing fee, and profits in Propositions 1 and 5, we can obtain $w^{*}<w_{n}<w_{c}$, $p^{*}<p_{n}<p_{c}$, and $f^{*}>f$. The price of any product in the endogenous model is higher than that of the exogenous model, which means that manufacturer's CSR level has effects on CSR-sensitive consumers and further affects customers' price sensitivity. But the patent license fee in the endogenous model is lower, which is set by the manufacturer to encourage the retailer to recycle and remanufacture. However, the manufacturer and the retailer's profits in the exogenous model are not necessarily more than those in endogenous model.

\section{Conclusion}

This study investigates the CLSC production and coordination problem by setting endogenous and exogenous CSR assumptions. CSR level can effectively improve the revenues of the manufacturer and the retailer, and patent licensing fee has an important regulatory effect on regulating the manufacturer's revenue and encouraging the retailer to remanufacture. CLSC considering CSR is more competitive than the traditional pure profit maximization supply chain. In practice, improving consumers' social responsibility consciousness and raising enterprises' level of CSR can achieve a win-win situation for revenues and social welfare. RS contracts coordinate the CLSC of endogenous and exogenous CSR.

From the comparisons and discussions of the results among the two models, we obtained some managerial insights. The manufacturer's level of CSR affects the wholesale price and patent licensing fee, and this result is significantly different from the profit maximization of a pure supply chain. Improving the social responsibility consciousness of consumers and raising the CSR level can achieve a win-win situation for revenues and social welfare; the manufacturer and the retailer should therefore increase the proportion of socially responsible consumers through the price mechanism. The results of sensitivity analysis reveal that the supply chain can be coordinated by using the compensation-based wholesale price mechanism. Therefore, the mechanism not only increases the profits of the CLSC and all members but also increases CSR activities for environmental, social, and economic development.

This study has several limitations and future research opportunities. This study adopts the linear demand. In terms of random demand, there remains an issue of how to solve the model. In addition, regarding the RS contract coordinating the supply chain adopted herein, we can try to adopt quantity discount contracts and bargaining models for coordination.

\section{Appendix}

\section{A. Proof of Proposition 3}

Proof of Proposition 3. The retailer's revenue function:

$$
\begin{aligned}
\pi_{R}= & (\lambda p-w)(a-a p)+\left(w-c_{n}+\Delta\right)(\alpha+\beta r) \\
& -(f+r)(\alpha+\beta r) .
\end{aligned}
$$

Take first derivation with respect to $p$ and $r$, and get $p^{\mathrm{co}}=((\lambda+w) / 2 \lambda)$ and $r^{\mathrm{co}}=\left(\left(-\alpha+\beta\left(w+\Delta-f-c_{n}\right)\right) / 2 \beta\right)$.

Let the profits of the CLSC under the revenue-sharing contract be the same as that under centralized decisions, and it needs to satisfy $((\lambda+w) / 2 \lambda)=\left(\left(\alpha-\alpha \theta+a c_{n}\right) /(2 a-a \theta)\right)$, $\left.\left(\left(-\alpha+\beta\left(w+\Delta-f-c_{n}\right)-a \theta\right) / 2 \beta\right)=((\beta \Delta-\alpha) / 2 \beta)\right)$.

The manufacturer's optimum wholesale price and patent licensing fee are

$$
\begin{aligned}
& w^{\mathrm{co}}=\frac{2 c_{n}-\theta}{(2-\theta)} \lambda, \\
& f^{\mathrm{co}}=\frac{2 c_{n}-\theta}{(2-\theta)} \lambda-c_{n} .
\end{aligned}
$$

At this point, the revenues of the manufacturer and the retailer are

$$
\begin{aligned}
& v_{M}^{\mathrm{co}}=\frac{a\left(-c_{n}\right)^{2}(\theta+2 \lambda-2)}{2(2-\theta)^{2}}, \\
& \pi_{R}^{\mathrm{co}}=\frac{4 a \lambda \beta\left(1-c_{n}\right)^{2}+(2-\theta)^{2}(\alpha+\beta \Delta)^{2}}{4 \beta(2-\theta)^{2}} .
\end{aligned}
$$

The condition of both parties receiving the contract is $v_{M}^{\mathrm{co}}>v_{M}^{*}$ and obtain $\lambda_{1}<\lambda<\lambda_{2}$ : 


$$
\begin{aligned}
& \lambda_{1}=\frac{(2-\theta)^{2}\left(16 a\left(1-c_{n}\right)^{2}-3(4-\theta)^{2}(\alpha+\beta \Delta)^{2}\right)}{16 a \beta(4-\theta)^{2}\left(-c_{n}\right)^{2}}, \\
& \lambda_{2}=-\left(\frac{a\left(1-c_{n}\right)^{2}}{2(\theta-2)}+\frac{4 a \beta\left(1-c_{n}\right)^{2}+(4-\theta)(\alpha+\beta \Delta)^{2}-3 \beta^{2} \Delta^{2} \theta}{8 \beta(4-\theta)}\right) \frac{(2-\theta)^{2}}{a\left(1-c_{n}\right)^{2}} .
\end{aligned}
$$

\section{B. Proof of Proposition 8}

Proof of Proposition 8. The retailer' s revenue function is

$$
\begin{aligned}
\pi_{R}= & \left(\lambda p_{c}-w_{c}\right) a \rho\left(1-p_{c}+K y_{m}\right) \\
& +\left(\lambda p_{n}-w_{n}\right) a(1-\rho)\left(1-p_{n}\right)+(\Delta-f-r)(\alpha+\beta r) .
\end{aligned}
$$

Take the first derivation respects to $p_{c}, p_{n}$, and $r$ and obtain $p_{c}=\left(\left(\lambda+w_{c}+K \lambda y_{m}\right) / 2 \lambda\right), p_{n}=\left(\left(\lambda+w_{n}\right) / 2 \lambda\right)$, and $r=-((\alpha-\beta \Delta) / 2 \beta)$.

Let the profits of the CLSC under the revenue-sharing contract be the same as that under centralized decisions, and it needs to satisfy $\left(\left(\lambda+w_{c}+K \lambda y_{m}\right) / 2 \lambda\right)=-\left(\left(2+2 c_{n}-\right.\right.$ $\left.\left.\operatorname{ac} \rho K^{2}\right) / a \rho K^{2}-4\right)$ and $\left(\left(\lambda+w_{n}\right) / 2 \lambda\right)=\left(\left(1+c_{n}\right) / 2\right)$.

The optimal wholesale price and the patent licensing fee of the manufacturer are $w_{c}=-2 \lambda\left(\left(\left(2+2 c_{n}-a c_{n} \rho K^{2}\right) /\right.\right.$ $\left.\left.\left(a \rho K^{2}-4\right)\right)+\left(\left(\lambda+K \lambda y_{m}\right) / 2 \lambda\right)\right), \quad w_{n}=\lambda c_{n}$, and $f=((\alpha+$ $\beta \Delta) / 2 \beta)$.

The total revenue under the coordinated decision should be greater than the total revenue under the decentralized decision, $\left(\pi_{M}+\pi_{R}\right)^{\text {co }}>\left(\pi_{M}+\pi_{R}\right)^{*}$, and we can obtain $\lambda_{1}$ and $\lambda_{2}$, satisfying $\lambda_{1}<\lambda<\lambda_{2}$.

\section{Data Availability}

The data used to support the findings of this study are available from the corresponding author upon request.

\section{Conflicts of Interest}

The authors declare that there are no conflicts of interest regarding the publication of this paper.

\section{Acknowledgments}

This study was financially supported by Natural Science Foundation of Hunan Province (No. 2020JJ5011), Scientific Research Fund of Hunan Provincial Education Department (No. 19C0315) and National Natural Science Foundation of China (Nos. 71771080 and 71802075).

\section{References}

[1] Z. Hong and X. Guo, "Green product supply chain contracts considering environmental responsibilities," Omega, vol. 83, pp. 155-166, 2019.

[2] K. M. Amaeshi, O. K. Osuji, and P. Nnodim, "Corporate social responsibility in supply chains of global brands: a boundaryless responsibility? Clarifications, exceptions and implications," Journal of Business Ethics, vol. 81, no. 1, pp. 223-234, 2008.
[3] J. Cotte and R. Trudel, "Socially conscious consumerism:a systematic review of the body of knowledge," in Network for Business Sustainability Knowledge Project Series. Economist, Boston University, Boston, MA, USA, 2009.

[4] J. Gaur, M. Amini, and A. K. Rao, "Closed-loop supply chain configuration for new and reconditioned products: an integrated optimization model," Omega, vol. 66, pp. 212-223, 2017.

[5] C.-F. Hsueh, "Improving corporate social responsibility in a supply chain through a new revenue sharing contract," International Journal of Production Economics, vol. 151, no. 3, pp. 214-222, 2014.

[6] C.-F. Hsueh, "A bilevel programming model for corporate social responsibility collaboration in sustainable supply chain management," Transportation Research Part E: Logistics and Transportation Review, vol. 73, pp. 84-95, 2015.

[7] C.-H. Wu, "Collaboration and sharing mechanisms in improving corporate social responsibility," Central European Journal of Operations Research, vol. 24, no. 3, pp. 681-707, 2016.

[8] S. Panda, N. M. Modak, and L. E. Cárdenas-Barrón, "Coordinating a socially responsible closed-loop supply chain with product recycling," International Journal of Production Economics, vol. 188, no. 1, pp. 11-21, 2017.

[9] S. La and B. Choi, "Perceived justice and CSR after service recovery," Journal of Services Marketing, vol. 33, no. 2, pp. 206-219, 2019.

[10] J. M. Cruz, "The impact of corporate social responsibility in supply chain management: multicriteria decision-making approach," Decision Support Systems, vol. 48, no. 1, pp. 224-236, 2009.

[11] D. Zhao, H. Chen, X. Hong, and J. Liu, "Technology licensing contracts with network effects," International Journal of Production Economics, vol. 158, pp. 136-144, 2014.

[12] Y. Huang and Z. Wang, "Closed-loop supply chain models with product take-back and hybrid remanufacturing under technology licensing," Journal of Cleaner Production, vol. 142, pp. 3917-3927, 2016.

[13] X. Hong, K. Govindan, L. Xu, and P. Du, "Quantity and collection decisions in a closed-loop supply chain with technology licensing," European Journal of Operational Research, vol. 256, no. 3, pp. 820-829, 2017.

[14] S. Hao, Y. Jun, H. Jin-song, D. A. Qing-li, and W. Kai, "Research on the game strategies for the OEM and the remanufacturer under different decision structures," Chinese Journal of Management Science, vol. 25, no. 1, pp. 160-169, 2017.

[15] Y. Huang and Z. Wang, "Information sharing in a closed-loop supply chain with technology licensing," International Journal of Production Economics, vol. 191, pp. 113-127, 2017.

[16] L. Jin, B. Zheng, and X. Hu, "Patent licensing, production outsourcing and corporate social responsibility," Nankai Business Review, vol. 22, no. 3, pp. 40-53, 2019.

[17] D. Ni and K. W. Li, "A game-theoretic analysis of social responsibility conduct in two-echelon supply chains," International Journal of Production Economics, vol. 138, no. 2, pp. 303-313, 2012.

[18] S. Panda, "Coordination of a socially responsible supply chain using revenue sharing contract," Transportation Research Part E: Logistics and Transportation Review, vol. 67, pp. 92-104, 2014. 
[19] N. M. Modak, S. Panda, S. S. Sana, and M. Basu, "Corporate social responsibility, coordina tion and profit distribution in a dual-channel supply chain," Pacific Science Review, vol. 16, no. 4, pp. 235-249, 2015.

[20] S. Panda, N. M. Modak, and D. Pradhan, "Corporate social responsibility, channel coordination and profit division in a two-echelon supply chain," International Journal of Management Science and Engineering Management, vol. 11, no. 1, pp. 22-33, 2016.

[21] S. Panda and N. M. Modak, "Exploring the effects of social responsibility on coordination and profit division in a supply chain," Journal of Cleaner Production, vol. 139, pp. 25-40, 2016.

[22] C. L. White, A. E. Nielsen, and C. Valentini, "CSR research in the apparel industry: a quantitative and qualitative review of existing literature," Corporate Social Responsibility and Environmental Management, vol. 24, no. 5, pp. 382-394, 2017.

[23] N. M. Modak, N. Kazemi, and L. E. Cárdenas-Barrón, "Investigating structure of a two-echelon closed-loop supply chain using social work donation as a corporate social responsibility practice," International Journal of Production Economics, vol. 207, pp. 19-33, 2019.

[24] S. Panda, N. M. Modak, M. Basu, and S. K. Goyal, "Channel coordination and profit distribution in a social responsible three-layer supply chain," International Journal of Production Economics, vol. 168, pp. 224-233, 2015.

[25] C.-T. Zhang and M. Ren, "Closed-loop supply chain coordination strategy for the remanufacture of patented products under competitive demand," Applied Mathematical Modelling, vol. 40, no. 13-14, pp. 6243-6255, 2016.

[26] S. M. Seyedhosseini, S.-M. Hosseini-Motlagh, M. Johari, and M. Jazinaninejad, "Social price-sensitivity of demand for competitive supply chain coordination," Computers \& Industrial Engineering, vol. 135, pp. 1103-1126, 2019.

[27] S.-M. Jazinaninejad, M. Nouri-Harzvili, T.-M. Choi, and S. Ebrahimi, "Reverse supply chain systems optimization with dual channel and demand disruptions: sustainability, CSR investment and pricing coordination," Information Sciences, vol. 503, pp. 606-634, 2019.

[28] S.-M. Hosseini-Motlagh, S. Ebrahimi, and R. Zirakpourdehkordi, "Coordination of dual-function acquisition price and corporate social responsibility in a sustainable closed-loop supply chain," Journal of Cleaner Production, vol. 251, pp. 1-15, 2020.

[29] J. Li and S. Gong, "Coordination of closed-loop supply chain with dual-source supply and low-carbon concern," Complexity, vol. 202014 pages, 2020.

[30] I. S. Bakal and E. Akcali, "Effects of random yield in remanufacturing with price-sensitive supply and demand," Production \& Operations Management, vol. 15, no. 3, pp. 407-420, 2006. 